\title{
Metapelopia corbii gen. n., sp. n., a new Tanypodinae (Diptera: Chironomidae) from the Neotropical Region
}

\author{
Fabio Laurindo da Silva, Caroline Silva Neubern de Oliveira* and Susana Trivinho-Strixino \\ Laboratório de Ecologia de Insetos Aquáticos, Departamento de Hidrobiologia, Universidade Federal de São Carlos, C. P. 676, \\ 13565-905, São Carlos, SP, Brazil
}

Received 18 June 2013; Accepted 26 November 2013

\begin{abstract}
The new genus Metapelopia is established for species of Pentaneurini from the southeast Brazil. Generic diagnoses for larva, pupa and adult male are provided together with descriptions of all life stages of the new species Metapelopia corbii. The pupa and larva of an additional species in Metapelopia is described, but not formally named. In addition, keys to the males, pupae and larvae of genera in the Thienemannimyia group are provided.
\end{abstract}

Key words: Brazil / Metapelopia / Thienemannimyia group / Neotropical / taxonomy

\section{Introduction}

Non-biting midges of the Thienemannimyia group (Diptera: Chironomidae) are small dipterans with worldwide distribution, often found in streams, river and lakes. The group belonging to Pentaneurini tribe was erected by Fittkau (1962) as the "Thienemannimyia-Reihe". The adult males can be primarily recognized by hypopygium with complex dorsomedial lobes (aedeagal lobes). These are very characteristic for each species and usually possess lateral and basal hairs of variable form. However, they never form a complex of blades and filaments as in Ablabesmyia (Roback, 1971). Most pupae can be distinguished by having the abdominal segments with dense shagreen of longish, upright, mostly multi-branched or bifid spinules (Fittkau and Murray, 1986). Whereas, the ring organ of maxillary palp situated in distal $1 / 3$ of basal segment, pecten hypopharyngis without a strong corner tooth or a long teeth in middle of row and pseudoradula not linked to sclerotized zone basally are the diagnostic characters for most larvae (Fittkau and Roback, 1983).

The Thienemannimyia group comprises 12 valid genera: Amnihayesomyia Niitsuma, Arctopelopia Fittkau, Coffmania Hazra et Chaudhuri, Conchapelopia Fittkau, Hayesomyia Murray et Fittkau, Helopelopia Roback, Lobomyia Niitsuma, Meropelopia Roback, Rheopelopia Fittkau, Telopelopia Roback, Thienemannimyia Fittkau and Xenopelopia Fittkau. Despite some morphotypes have been described (Wiedenbrug, 2000; Trivinho-Strixino, 2011),

*Corresponding author: cneubern@yahoo.com.br the presence of species belonging to Thienemannimyia group is relatively uncommon in the Neotropical region. Recently, the examination of a Pentaneurini species, not readily identifiable, suggests that this species does not belong to any of the currently recognized genera, thus the genus, Metapelopia gen. n. is now erected for the species Metapelopia corbii sp. $\mathrm{n}$. The material in question had been reared from the larval stage and thus larval and pupal exuviae and adults male and female were available for study. Below two species of Metapelopia gen. n. are described, but only one is formally named since the association of adults with the immatures of the second species was not possible. In addition, keys to the males, pupae and larvae of genera in the Thienemannimyia group are provided.

\section{Material and methods}

Egg masses were collected using a drift net in a small stream in South-eastern Brazil. Hatched larvae were reared individually in the laboratory to obtain the associated pupal exuviae and adults. Additionally, larvae and one pupa were collected in small streams in Centralwestern and South-eastern Brazil. Larval skins, pupal exuviae and adults were preserved in $96 \%$ ethanol. Specimens examined were slide-mounted in Euparal.

Morphological terminology and abbreviations follow Sæther (1980). Data on larvae represent the 4th instar. Measurement methods followed Epler (1988). Mensural data are given as ranges, followed by the number 
of observed specimens in parenthesis if different from the number $(n)$ stated at the beginning of the description. Seta counts are given as the ranges only. The holotype and paratypes are deposited in the Reference Collection of Laboratório de Ecologia de Insetos Aquáticos (LEIA), Universidade Federal de São Carlos (UFSCar), São Carlos Brazil.

\section{Metapelopia gen. $\mathbf{n}$.}

\section{Type species. M. corbii sp. $n$.}

Etymology. Derived from the Greek meta, meaning among, along with, as the genus shares characters with Conchapelopia, Meropelopia and Thienemannimyia; and pelopia, a frequently used suffix in Tanypodinae, based on the suppressed Meigen 1800 genus name Pelopia. Gender of the genus name: feminine.

Generic diagnosis. The genus can be separated from other Tanypodinae by the combination of the following characters: adult with pedicel setose; scutal tubercle absent. Thorax with two supraalars; preepisternals setae present. Costa not produced beyond $\mathrm{R}_{4+5}$, ending between $\mathrm{M}_{1+2}$ and $\mathrm{M}_{3+4} \cdot \mathrm{R}_{2+3}$ present. Hypopygium with short volsella on median base of gonocoxite. Pupa with thoracic horn large, with spinules on the external membrane. Horn sac well developed, completely filling respiratory atrium and connected directly to the plastron plate. Plastron plate and corona present. External membrane reticulate. Thoracic comb and basal lobe absent. Larva with scattered swim hairs on body. S9, S10 and SSm forming a more or less straight line diagonal to longitudinal axis of head capsule, head index c. 0.90. Ring organ in proximal half of basal maxillary palp segment, b-sensillum two segmented. Ligula with five teeth, anterior toothed margin strongly concave.

\section{Generic description}

Adults

Head. Antenna with 14 flagellomeres. Temporal setae uniserial. Eyes bare, with dorsomedian extension. Cibarial pump with anterior margin concave. Palp developed normally.

Thorax. Antepronotal lobes separated medially. Dorsocentrals regularly uniserial. Lateral antepronotal and preepisternals setae present. Anepisternal and postnotal setae absent.

Wing. Membrane evenly covered with pale microtrichia. Costa not produced beyond $\mathrm{R}_{4+5}$, ending between $\mathrm{M}_{1+2}$ and $\mathrm{M}_{3+4} \cdot \mathrm{R}_{2+3}$ present. Base of radial sector absent. Brachiolum and squama setose.

Legs. Fore tibia with single spur. Mid and hind legs with two spurs. Hind tibial comb of five setae. All legs with slender, hook-shaped claws. Pulvilli well developed.

Hypopygium. Tergite IX with irregular row dorsal setae. Anal point present. Phallapodeme long and narrow.
Sternapodeme narrow. Gonocoxite cylindrical with slightly concave inner margin. Short volsella on median base of gonocoxite. Gonostylus broad, with apical megaseta.

\section{Pupa}

Cephalothorax. Wing sheath smooth. Thoracic horn with spinules on the external membrane; plastron plate large. Horn sac well developed, completely filling respiratory atrium and connected directly to the plastron plate. External membrane reticulate. Thoracic comb and basal lobe absent.

Abdomen. Tergites I-VIII with shagreen composed of longish, upright, mostly multi-branched or bifid spinules. Scar on T I present. T VII with four lateral setae. T VIII with five lateral setae. Abdominal segments with serrated border. Anal lobe with two anal macrosetae; outer margin with spinules. Genital sac smaller than anal lobe.

\section{Larva}

Head. With postoccipital margin dark brown. S9, S10 and SSm forming a more or less straight line diagonal to longitudinal axis of head capsule.

Antenna. Antenna four segmented; ring organ apically placed on basal segment.

Maxilla. Ring organ in proximal half of basal maxillary palp segment, b-sensillum two segmented.

Mandible. Slender, with small basal tooth with seta subdentalis.

Mentum and $M$ appendage. Dorsomental teeth reduced; pseudoradula granulation not organized into longitudinal rows.

Hypopharyngeal complex. Ligula with five teeth, tooth row deeply concave. Paraligula bifid, inner tooth shorter than outer tooth. Pecten hypopharyngis multitoothed.

Body. With some scattered swim hairs. Anterior parapods with simple claws. Posterior parapods with numerous simple claws, some slightly serrated; some of smaller claws darker. Anal tubules slender and short.

\section{Metapelopia corbii sp. $\mathrm{n}$.}

Type material. Holotype male with pupal and larval exuviae, Brazil, São Paulo, São Carlos, Fazzari reservoir, 27.xii.2003, J. J. Corbi. 7 Paratypes: two males and one female with pupal exuviae same data as holotype. One male and one female same data as holotype. One pupal exuviae same data as holotype. One larva same data as holotype except for Ipeúna, unnamed stream, without collection date, S. T. Strixino.

Etymology. Named in honor to Dr. Juliano José Corbi who first reared the hatched larvae in order to establish the associations between each life stage.

Diagnosis. As given in generic diagnosis of adult male. Pupa without strong spinules on abdominal segments. Larva with pecten hypopharyngis with 16 teeth. 


\section{Description}

Adult male ( $n=4$ unless otherwise stated)

Size. Total length 3.4-4.2 mm. Wing length 1.8-2.0 mm. Total length/wing length 1.79-2.13. Wing length/length of profemur 1.95-3.00.

Coloration. Head pedicel and antenna pale brown. Maxillary palp brown. Thorax pale brown; antepronotum pale. Wing membrane transparent with spots as in Fig. 1(C), covered with pale microtrichia. Legs as in Fig. 1(D-F). Abdominal coloration as in Figure 1(J). Hypopygium yellow.

Head (Fig. 1(A) and (B)). AR 1.53-1.73, flagellum 1093-1188 $\mu \mathrm{m}$ long, pedicel with 3-4 seate. Temporal setae 17-26. Eyes containing 3-4 terminal facets. Tentorium 177-208 $\mu \mathrm{m}$ long, stipes not measurable. Clypeus 112-119 (3) $\mu \mathrm{m}$ long, 97-118 (3) $\mu \mathrm{m}$ wide at largest part, bearing 25-30 setae. Cibarial pump 272-285 (3) $\mu \mathrm{m}$ long. Palpomere 1-5 lengths: 53-69; 91-108; 103-131, 146-189; 223-266 $\mu \mathrm{m}$.

Thorax. Antepronotum with 7-13 lateral setae. Acrostichals uncountable; dorsocentrals 24-37 (2); prealars 14-18; supraalars 2. Scutellum with 33-41 setae. Preepisternals 2-3.

Wing (Fig. 1(C)). Width 0.5-0.6 mm. Costa 1.6-1.7 $\mathrm{mm}$ long. WW 0.30-0.32. Brachiolum with two setae. Squama with 37-41 (3) setae.

Legs (Fig. 1(G-I)). Fore leg: width at apex of tibia 25-31 $\mu \mathrm{m}$, tibia with one apical spur 45-60 $\mu \mathrm{m}$ long and eight side teeth (Fig. 1(G)). Mid leg: width at apex of tibia 24-28 $\mu \mathrm{m}$, tibia with two apical spurs 54-57; 57-60 $\mu \mathrm{m}$ long, longest spur with nine to ten teeth (Fig. 1(H)). Hind leg: width at apex of tibia 27-34 $\mu \mathrm{m}$, tibia with two apical spurs 52-54; 72-79 $\mu \mathrm{m}$ long, longest spur with nine teeth (Fig. 1(I)). Lengths and proportions as in Table 1.

Hypopygium (Fig. 1(K)). Tergite IX with eight to nine (three) dorsal setae. Volsella slender, 51 (1) $\mu \mathrm{m}$ long. Phallapodeme 77-88 $\mu \mathrm{m}$ long. Gonocoxite 174-192 $\mu \mathrm{m}$ long. Gonostylus 125-134 $\mu \mathrm{m}$ long; megaseta 9-11 $\mu \mathrm{m}$ long. HR 1.40-151. HV 2.55-3.11.

\section{Adult female ( $n=2$ unless otherwise stated)}

Size. Total length 3.3-3.8 mm. Wing length 1.8-1.9 $\mathrm{mm}$. Total length/wing length 1.77-2.06. Wing length/ length of profemur 2.16-2.20.

Coloration. Head pedicel and antenna pale brown. Maxillary palp brown. Thorax pale brown; antepronotum pale. Wing membrane transparent with spots, covered with pale microtrichia. Legs, abdomen and genitalia as in male.

Head. Antenna unmeasureable, pedicel with four setae. Temporal setae 21-28. Eyes containing three to four (one) terminal facets. Tentorium 169 (1) $\mu \mathrm{m}$ long, stipes

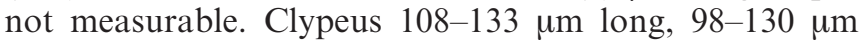
wide at largest part, bearing 44-57 setae. Cibarial pump
285-309 um long. Palpomere 1-5 lengths: 62-71; 111-118; 118-127, 176-186; 254-303 $\mu \mathrm{m}$.

Thorax. Antepronotum with seven lateral setae. Acrostichals uncountable; dorsocentrals 37-42; prealars 24-28; supraalars 2. Scutellum with 64 setae. Preepisternals 4.

Wing. Width $0.6-0.7 \mathrm{~mm}$. Costa $1.7 \mathrm{~mm}$ long. WW 0.34-0.39. Brachiolum with two setae. Squama with 35-37 (3) setae.

Legs. Fore leg: width at apex of tibia 28-29 $\mu \mathrm{m}$, tibia with one apical spur 46-52. Mid leg: width at apex of tibia $28-31 \mu \mathrm{m}$, tibia with two apical spurs $54-55 ; 62-63 \mu \mathrm{m}$ long. Hind leg: width at apex of tibia $33-35 \mu \mathrm{m}$, tibia with two apical spurs 51-54; 69-74 $\mu \mathrm{m}$ long. Lengths and proportions as in Table 2.

Genitalia (Fig. 1(L)). Gonapophysis VIII broadly rounded. Tergite IX 94 (1) $\mu \mathrm{m}$ wide at middle, without setae. Coxosternapodeme 188 (1) $\mu \mathrm{m}$ long. Tergite X with 8 (1) setae on each side. Postgenital plate rounded. Cerci quadrate to oval-quadrate, $78 \mu \mathrm{m}$ long and $50 \mu \mathrm{m}$ wide; with numerous setae. Notum length (from ramus forward) $144 \mu \mathrm{m}$. Seminal capsules oval with conical shaped necks, length $72 \mu \mathrm{m}$, maximum width $57 \mu \mathrm{m}$. Length ratio $\mathrm{SCa} / \mathrm{No} 0.50$.

\section{Pupa ( $n=5$ unless otherwise stated)}

Size. Male abdomen 3.9-4.1 (4) mm long. Female abdomen 4.2 (1) $\mathrm{mm}$ long.

Coloration. Exuviae yellow. Thoracic horn most pale brown.

Cephalothorax (Fig. 2(A)). Wing sheath 1230-1310 $\mu \mathrm{m}$ long and 450-460 $\mu \mathrm{m}$ wide. Thoracic horn as in Fig. 2(A), 277-309 $\mu \mathrm{m}$ long and 137-169 $\mu \mathrm{m}$ wide; plastron plate 121-146 $\mu \mathrm{m}$ long.

Abdomen (Fig. 2(B) and (C)). T I with scar, 188-201 $\mu \mathrm{m}$ long. Chaetotaxy as in Fig. 2(B). Anal lobe as in Fig. 2(B), 494-538 (4) $\mu \mathrm{m}$ long and 375-400 (4) $\mu \mathrm{m}$ wide. Genital sac 294-325 (4) $\mu \mathrm{m}$ long. GS/AL 0.58-0.66 (4).

\section{Larva ( $n=2$ unless otherwise stated)}

Coloration. Head pale yellow; distal tooth of mandible and apex of ligula brown. Abdomen pale yellow; procercus and anal setae brown. Posterior parapod claws pale yellow with some dark claws.

Head (Fig. 3(A)). Length 619-669 $\mu \mathrm{m}$, 563-625 $\mu \mathrm{m}$ wide; cephalic index 0.91-0.94. Chaetotaxy as in Fig. 3(A).

Antenna. Length 377-394 $\mu \mathrm{m}$ long, $\mathrm{A}_{1}$ 311-328 $\mu \mathrm{m}$ long, with ring organ placed 200-223 $\mu \mathrm{m}$ from base, $\mathrm{A}_{2} 54$ um long. AR 4.71-4.95.

Maxilla (Fig. 3(B)). Basal palp segment 62-65 $\mu \mathrm{m}$ long and $14 \mu \mathrm{m}$ wide, with ring organ 19-22 $\mu \mathrm{m}$ from base. $\mathrm{A}_{1} / \mathrm{P}_{1}$ 5.05-5.07, $\mathrm{A}_{2} / \mathrm{P}_{1}$ 0.83-0.88.

Mandible (Fig. 3(C)). Length 135-151 $\mu \mathrm{m}$, with three lateral setae, basal tooth 39-40 from apex, accessory tooth absent. $\mathrm{A}_{1} / \mathrm{MD} 2.18-2.30$.

Mentum and $M$ appendage (Fig. 3(D)). As given in generic description. 


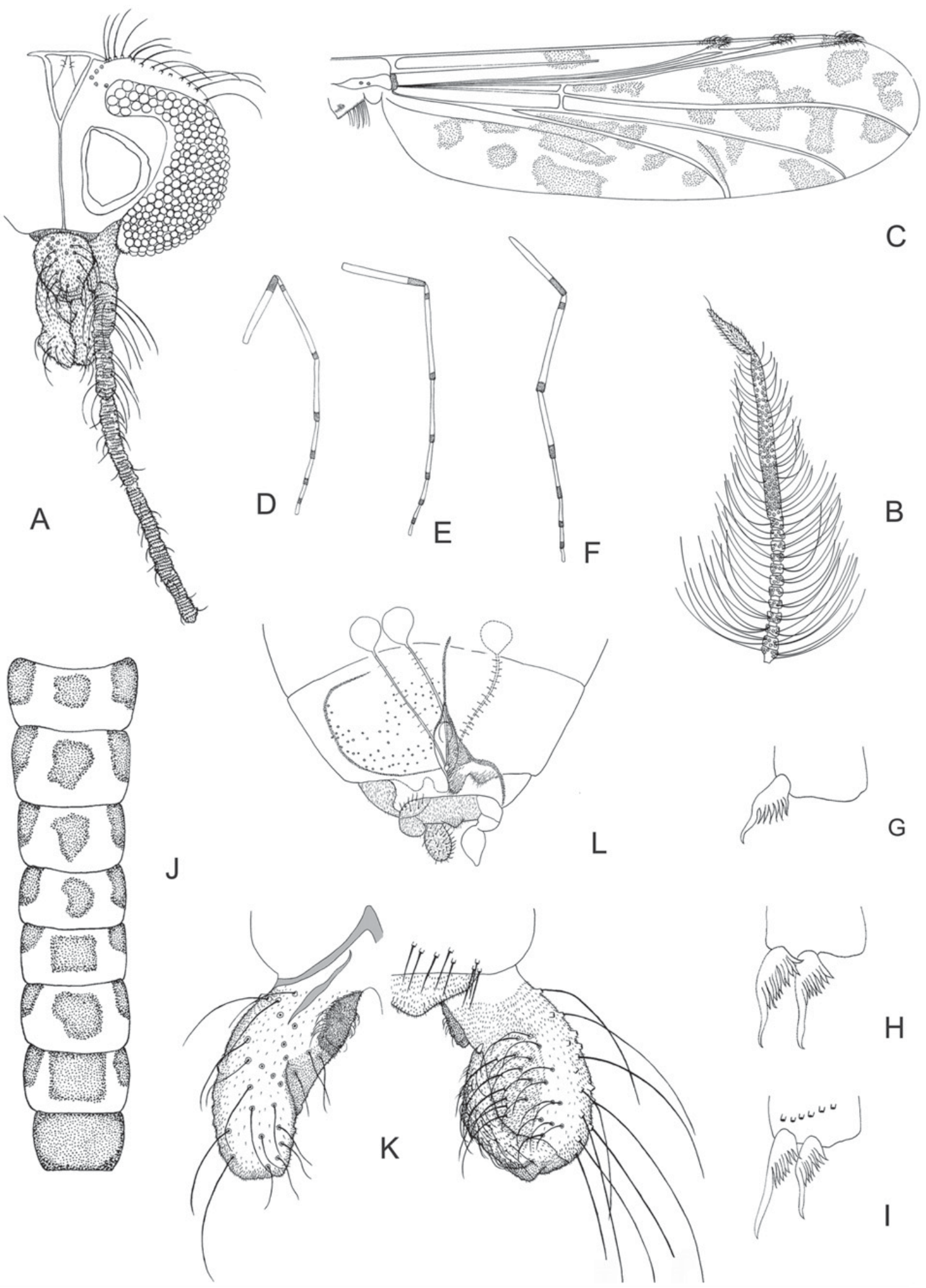

Fig. 1. Metapelopia corbii sp. n.: adult male. (A) Head, frontal view. (B) Antenna. (C) Wing. Fore leg (D), mid leg (E), hind leg (F). Tibial spurs of (G) fore leg, (H) mid, (I) hind. (J) Abdomen without hypopygium. (K) Hypopygium. Adult female. (L) Genitalia.

Hypopharyngeal complex (Fig. 3(E) and (F)). Muscle attachment 25-27 long. Paraligula 45Ligula 77-80 $\mu \mathrm{m}$ long, maximum width $51-53 \mu \mathrm{m} . \quad 46 \mu \mathrm{m}$ long. Pecten hypopharyngis with 16 teeth It $/ \mathrm{O} \quad 0.37-0.63 . \quad \mathrm{Mt} / \mathrm{O} \quad 0.48-0.51 . \quad \mathrm{It} / \mathrm{Li} \quad 0.13-0.19 . \quad$ (Fig. 3(F)). 
Table 1. Lengths (in $\mu \mathrm{m})$ and proportions of leg segments in Metapelopia corbii sp. n., male $(n=3-4)$.

\begin{tabular}{|c|c|c|c|c|c|}
\hline & $\mathrm{Fe}$ & $\mathrm{Ti}$ & $\mathrm{ta}_{1}$ & $\mathrm{ta}_{2}$ & $\mathrm{ta}_{3}$ \\
\hline$\overline{p_{1}}$ & $631-923$ & $1031-1092$ & $692-769$ & $400-446$ & $307-323$ \\
\hline $\mathrm{p}_{3}$ & $795-892$ & $1108-1231$ & $754-815$ & $446-477$ & $308-369$ \\
\hline $\mathrm{p}_{1}$ & $215-231$ & $138-154$ & $0.67-0.75$ & $2.19-2.47$ & $2.24-2.67$ \\
\hline $\mathrm{p}_{2}$ & $169-231$ & $123-139$ & $0.57-0.64$ & $2.59-3.13$ & $2.91-3.57$ \\
\hline $\mathrm{p}_{3}$ & 231 & 139-169 & $0.66-0.68$ & $2.27-2.39$ & $2.47-2.65$ \\
\hline
\end{tabular}

Table 2. Lengths (in $\mu \mathrm{m}$ ) and proportions of leg segments in Metapelopia corbii sp. n., female $(n=2)$.

\begin{tabular}{|c|c|c|c|c|c|}
\hline & $\mathrm{Fe}$ & $\mathrm{Ti}$ & $\mathrm{ta}_{1}$ & $\mathrm{ta}_{2}$ & $\mathrm{ta}_{3}$ \\
\hline$\overline{p_{1}}$ & 846 & $985-1077$ & $585-662$ & $339-369$ & $246-262$ \\
\hline $\mathrm{p}_{2}$ & $692-969$ & $923-1046$ & $554-569$ & 308 & 231 \\
\hline $\mathrm{p}_{3}$ & 862 & $1139-1185$ & $708-785$ & $446-462$ & $323-354$ \\
\hline & $\mathrm{ta}_{4}$ & $\mathrm{ta}_{5}$ & LR & BV & SV \\
\hline $\mathrm{p}_{1}$ & 200 & 139 & $0.59-0.61$ & $2.62-2.67$ & $2.91-3.13$ \\
\hline $\mathrm{p}_{2}$ & 169 & $123-139$ & $0.54-0.60$ & $2.78-2.89$ & $3.05-3.42$ \\
\hline $\mathrm{p}_{3}$ & $215-231$ & 139 & $0.62-0.66$ & $2.39-2.41$ & $2.61-2.83$ \\
\hline
\end{tabular}

Body (Fig. 3(G)). Procercus 150-154 $\mu \mathrm{m}$ long, 41-46 $\mu \mathrm{m}$ wide, with seven anal setae 900-938 $\mu \mathrm{m}$ long. $\mathrm{L} / \mathrm{W}$ 3.33-3.66. Supraanal seta 675-700 $\mu \mathrm{m}$ long. Anal tubules 238 (1) $\mu \mathrm{m}$ long.

\section{Metapelopia sp.}

Material. one pupa, Brazil, Goiás, Trindade, vii.2010, C. S. C. Araújo. Two prepupae as previous.

\section{Description}

Pupa $(n=1)$

Size. Male abdomen $4.7 \mathrm{~mm}$ long.

Coloration. Exuviae brown. Thoracic horn most pale brown.

Cephalothorax (Fig. 4(A)). Wing sheath smooth $1540 \mu \mathrm{m}$ long and $550 \mu \mathrm{m}$ wide. Thoracic horn as in Fig. 4(A), $340 \mu \mathrm{m}$ long and $177 \mu \mathrm{m}$ wide; plastron plate $183 \mu \mathrm{m}$ long.

Abdomen (Fig. 4(B)). Similar to M. corbii sp. n. Anal lobe as in Fig. 4(B), $625 \mu \mathrm{m}$ long and 450 (4) $\mu \mathrm{m}$ wide, with two anal macrosetae; outer margin with spinules. Genital sac smaller than anal lobe, with $356 \mu \mathrm{m}$ long. GS/AL 0.57.

\section{Larva ( $n=2$ unless otherwise stated)}

Similar to $M$. corbii sp. n. except for:

Coloration. Half-length of mandible brown.

Head (Fig. 4(C)). Length $706 \mu \mathrm{m}, 631-656 \mu \mathrm{m}$ wide; cephalic index 0.89-0.92.

Antenna. Length 403-411 $\mu \mathrm{m}$ long, $\mathrm{A}_{1}$ 341-348 $\mu \mathrm{m}$ long, with ring organ placed 219-231 $\mu \mathrm{m}$ from base, $\mathrm{A}_{2}$ 49-53 um long. AR 5.51-5.54.
Maxilla (Fig. 4(D)). Basal palp segment 62-65 $\mu \mathrm{m}$ long and $15 \mu \mathrm{m}$ wide, with ring organ 20-23 $\mu \mathrm{m}$ from base. $\mathrm{A}_{1} / \mathrm{P}_{1}$ 5.28-5.65, $\mathrm{A}_{2} / \mathrm{P}_{1}$ 0.80-0.82.

Mandible (Fig. 4(E)). Length 139-151 $\mu \mathrm{m}$, basal tooth 43-46 from apex. A $/$ MD 2.31-2.46.

Hypopharyngeal complex (Fig. 4(F) and (G)). Ligula 87-100 $\mu \mathrm{m}$ long, maximum width 57-62 $\mu \mathrm{m}$. It/O 0.28-0.54. Mt/O 0.46-0.52. It/Li 0.10-0.17. Muscle attachment 17-19 long. Paraligula 44-59 $\mu \mathrm{m}$ long. Pecten hypopharyngis with 13 teeth (Fig. 4(G)).

Body. With some scattered hairs. Anterior parapods with simple claws. Procercus 152-172 $\mu \mathrm{m}$ long, 37-42 $\mu \mathrm{m}$ wide, with seven anal setae 650-700 $\mu \mathrm{m}$ long. L/W 4.13-4.15. Supraanal seta unmeasureable. Anal tubules $400 \mu \mathrm{m}$ long. Posterior parapods with numerous simple claws some slightly serrated; some of smaller claws darker.

\section{Systematics}

All stages of Metapelopia conform to diagnoses of the tribe Pentaneurini, but each differs in generic identity according to respective stage keyed. In the male adults key in Murray and Fittkau (1989) Metapelopia will key to couplet 24, containing the genera Arctopelopia, Meropelopia, Rheopelopia and Thienemannimyia. The new genus possesses diffused features with the other genera of the Thienemannimyia group and appears to be related to genus Rheopelopia and Thienemannimyia because of apex of femora with brown ring and volsella short. However, the finger-like lateral lobe present in Rheopelopia and the quadrate median volsella as noted in Thienemannimyia distinguish these genera from Metapelopia. Similarly in the key to pupal tanypod of the Holarctic region in Fittkau and Murray (1986), Metapelopia will key to couplet 28, comprising the genera Conchapelopia, Helopelopia, Meropelopia and Telopelopia. 

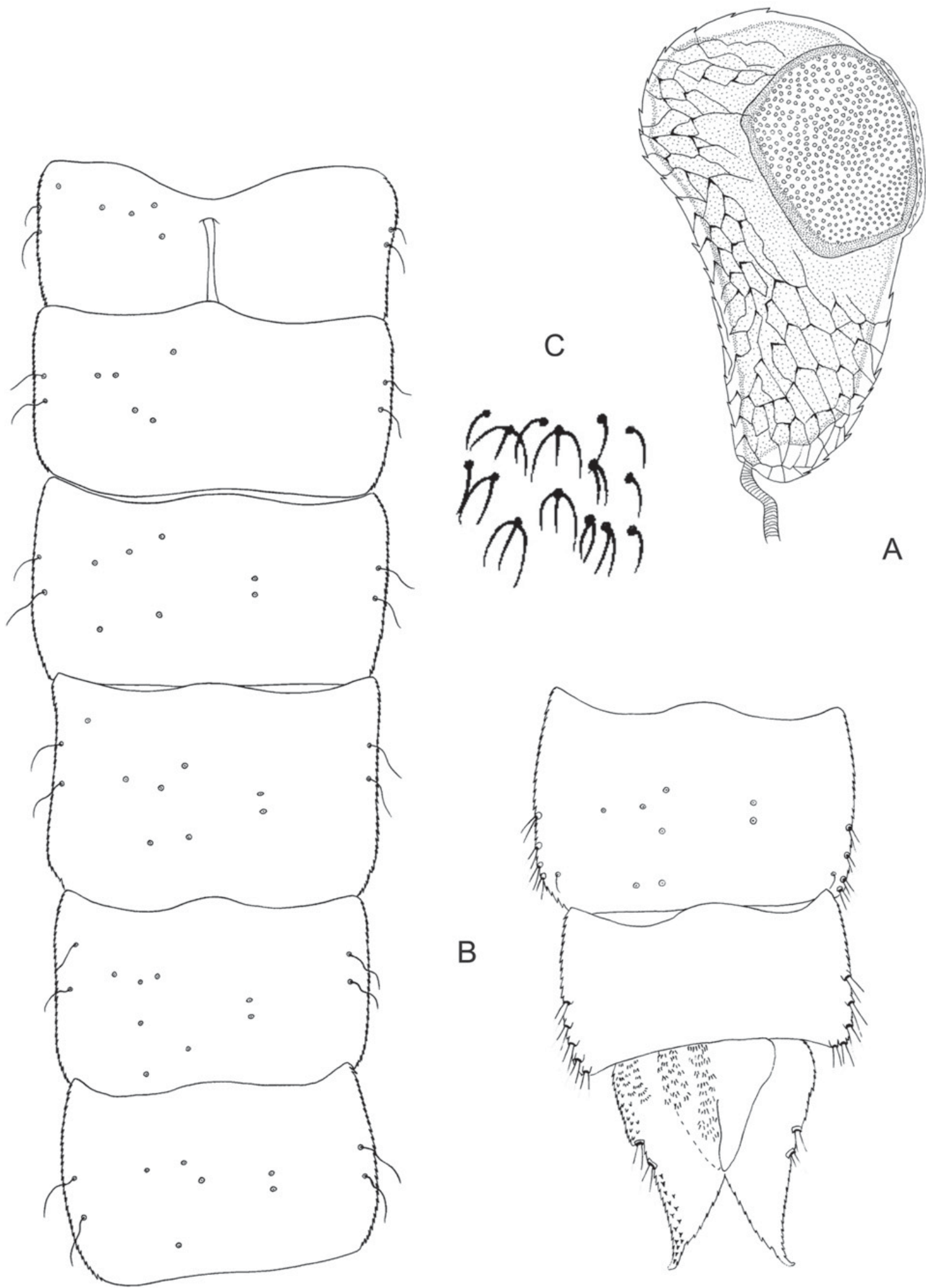

Fig. 2. Metapelopia corbii sp. n.: pupa. (A) Thoracic horn. (B) Abdominal segments with chaetotaxy and anal lobe with male genital sac, right: ventral aspect, left: dorsal aspect. (C) Shagreen pattern on abdominal segments surface.

The pupa of Metapelopia corbii has plastron plate exceptionally large as observed in Conchapelopia, but the absence of thoracic comb can separate the new species from this genus. The presence of corona and absence of thoracic comb comes nearer to Helopelopia, but the thoracic horn with external membrane not reticulate 

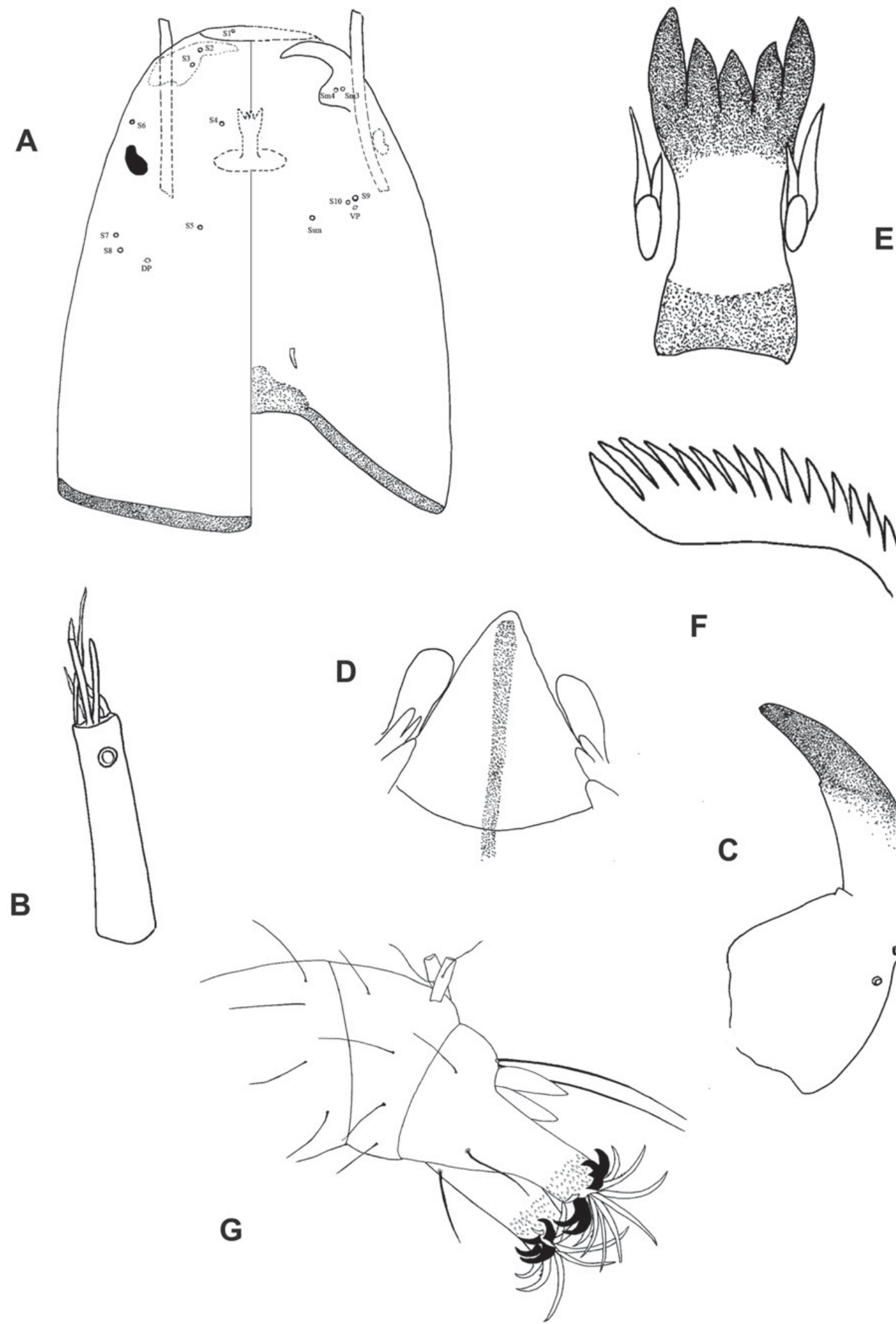

$\mathbf{F}$

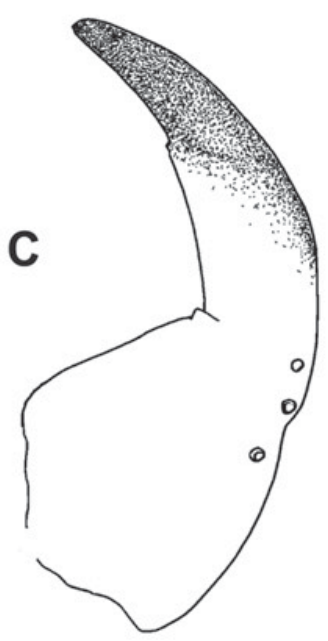

Fig. 3. Metapelopia corbii sp. n.: larva. (A) Head with chaetotaxy, left: dorsal aspect, right: ventral aspect. (B) Maxillary palp detail. (C) Mandible. (D) Mentum and M appendage. (E). Ligula and paraligula. (F) Pecten hypopharyngis. (G) Abdominal rear.

distinguishes the latter from Metapelopia. In the key to larval tanypod of the Holarctic region in Fittkau and Roback (1983), Metapelopia will key to couplet
34 consisting of the Arctopelopia, Meropelopia and Thienemannimyia. The larvae of Metapelopia corbii has pseudoradula uniformly broad, posterior margin of head 

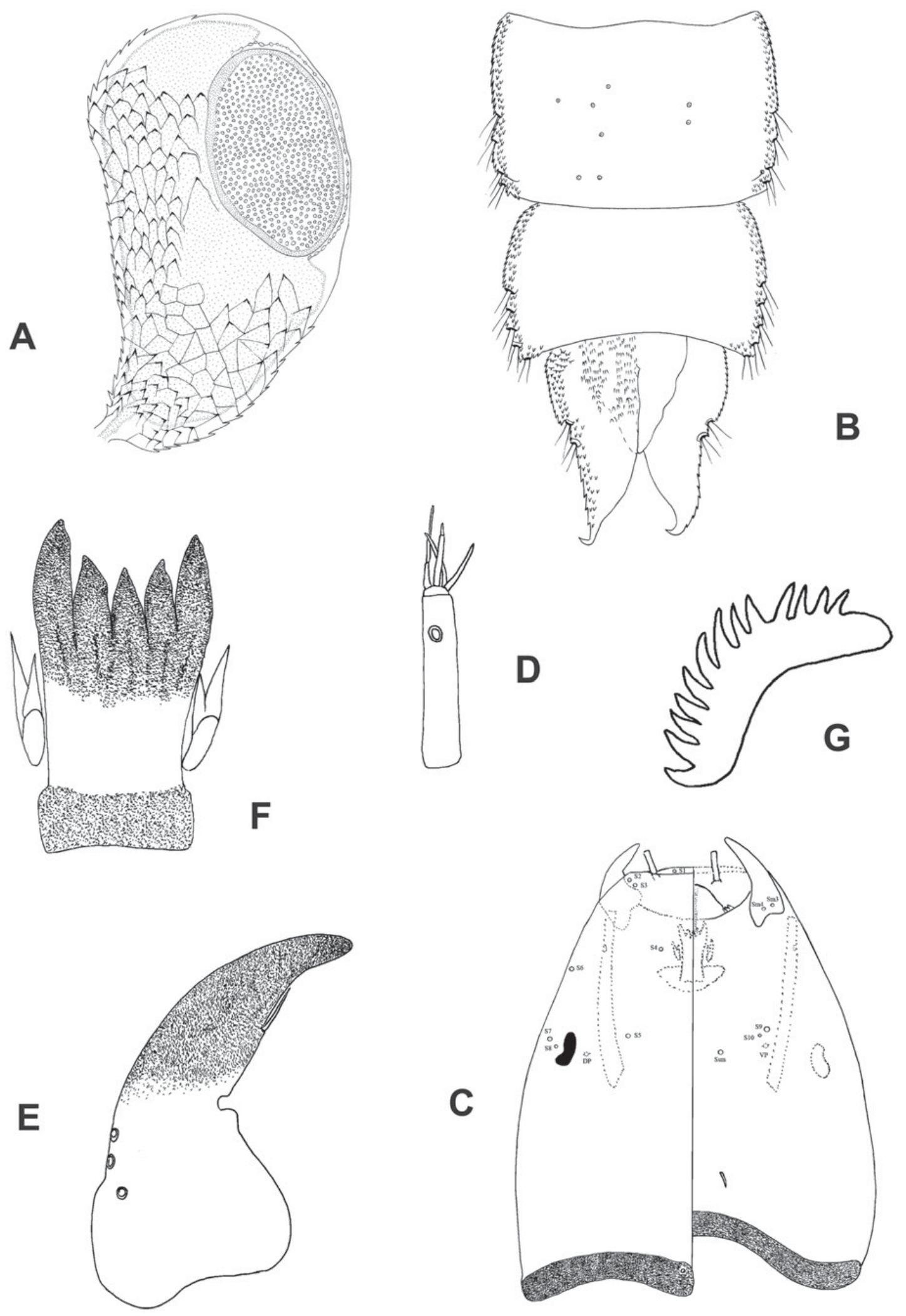

Fig. 4. Metapelopia sp. 1: pupa. (A) Thoracic horn. (B) Abdominal segments VII-VIII with chaetotaxy and anal lobe with male genital sac, right: ventral aspect, left: dorsal aspect. Larva. (C) Head with chaetotaxy, left: dorsal aspect, right: ventral aspect. (D) Maxillary palp detail. (E) Mandible. (F). Ligula and paraligula. (G) Pecten hypopharyngis. 
capsule dark brown and second antennal segment length about $40 \mu \mathrm{m}$, differing from the three aforementioned genera, which possess pseudoradula with middle section broadened, posterior margin of head capsule pale and second antennal segment length about $50 \mu \mathrm{m}$, respectively. The following keys allow distinguishing accurately Metapelopia from the other genera in the Thienemannimyia group. group

Key to adult males of genera in the Thienemannimyia

1. Segment VIII over-reaching tergite IX. Anal point longer than wide. Tibial spurs with only $2-3$ side teeth; tarsi with sensillae chaetica .........Xenopelopia Fittkau

- Segment VIII not over-reaching tergite IX. Anal point wider than long. Tibial spurs with at least five side teeth; tarsi without sensillae chaetica ....................... 2

2. Scutal tubercle present .......................................... 3

- Scutal tubercle absent ............................................. 9

3. Median volsella bilobed and pubescent .................... 4

- Median volsella elongate with complete or partial row of filaments ............................................................. 7

4. Setae on median volsella arising from distinct tubercles; phallapodeme long, broadened anteriorly ......... Amnihayesomyia Niitsuma

- Setae on median volsella not arising from distinct tubercles; phallapodeme not broadened anteriorly ................................................................. 5

5. Gonostylus medially bent nearly to a right angle; sternapodeme with round anterior projection ............

Lobomyia Niitsuma

- Gonostylus medially bent but not to a right angle; sternapodeme with an inverted V-shape anterior projection

6. Gonostylus gradually tapering towards the apex; phallapodeme simple with slender anterior part ........ Coffmania Hazra et Chaudhuri

- Gonostylus abruptly narrows before the apex; phallapodeme forked, broadened anteriorly Hayesomyia Murray et Fittkau

7. Gonocoxite upwardly curved and narrow posteriorly. Dorsomedian seta arising from distinct tubercle. Gonostylus straight, inserted dorsally on gonocoxite. Tarsomere 3 of mid leg without apical brush of setae. Preepisternal setae absent .......... Telopelopia Roback

- Gonocoxite not as above. Dorsomedian setae not arising from tubercle. Gonostylus medially bend, inserted terminally on gonocoxite. Tarsomere 3 of mid leg with apical brush. Preepisternal setae present ........................................................... 8

8. Abdominal tergite VIII with pair of conspicuous setal tufts. Gonostylus with apical expansion forming a hood over the megaseta ............ Helopelopia Roback

- Abdominal tergite VIII without tufts of setae. Gonostylus without apical expansion Conchapelopia Fittkau
9. Volsella short with or without basolateral digitiform appendage. Gonocoxite almost cylindrical. Apex of femora and/or base of tibiae with or without brown ring 10

- Volsella elongate with basolateral digitiform appendage. Gonocoxite cylindrical or with anterior concavity. Femora and tibiae without bands or rings .....

10. Femora with apical brown ring; tarsomere 3 of mid leg with apical brush of setae. Posterior border of tergite IX concave Rheopelopia Fittkau

- Femora with or without apical ring; tarsomere 3 of mid leg without apical brush of setae. Posterior border of tergite IX straight or slightly convex ......11 11. Median volsella elongate; phallapodeme simple Metapelopia n. gen.

- Median volsella broad; phallapodeme forked Thienemannimyia Fittkau

12. Tibial comb present on hind legs. Volsella reaching almost $3 / 4$ long as gonocoxite, with short filaments and short digitiform basolateral appendage Meropelopia Roback

- Tibial comb absent on hind legs. Volsella reaching $1 / 2$ long as gonocoxite, setose and with long, basolateral digitiform appendage .................Arctopelopia Fittkau

Key to pupae of genera in the Thienemannimyia group

1. Abdominal segments with a sparse shagreen of small spinules ..................................... Xenopelopia Fittkau

- Abdominal segments with a dense shagreen of longish, upright, multi-branched or bifid

2. Segment VII without LS setae. Horn sac indistinct. Aeropyle absent. Anal lobe distally constricted and outwardly directed Rheopelopia Fittkau

- Segment VII with 2-5 LS setae. Horn sac distinct or if reduced, then plastron plate or aeropyle clearly visible. Anal lobe symmetrically tapering, not curved outwards 3

3. Thoracic horn without plastron plate. Horn sac well developed or reduced

- Thoracic horn with plastron plate. Horn sac well developed .......................................................... 7

4. Abdominal segments II-VI with six LS setae. Horn sac much reduced, simple or distally expanded, occasionally with an indistinct aeropyle Thienemannimyia Fittkau

- Abdominal segments II-VI with only two LS setae. Horn sac well developed or somewhat reduced. Aeropyle present or absent .................................... 5

5. Abdominal segment VII with two LS setae Lobomyia Niitsuma

- Abdominal segment VII with 4-5 LS setae ............. 6

6. Thoracic horn tubular, rounded apically. Horn sac a much wrinkled tube. Aeropyle not distinct. Corona not distinct 
- Thoracic horn club-shaped, flattened. Horn sac distally expanded, ending in a short neck connected to a distinct aeropyle. Corona distinct

Hayesomyia Murray et Fittkau

7. Plastron plate exceptionally large, as wide as the maximum horn width. Thoracic comb present but weakly developed

- Plastron plate not exceptionally large, its maximum diameter about $1 / 2$ maximum horn width. Thoracic comb present or absent

8. Tergite I with indistinct scar. Thoracic comb present. Abdominal segment VIII with three normal and two reduced LS setae Amnihayesomyia Niitsuma

- Tergite I with distinct scar. Thoracic comb present but weakly developed. Abdominal segment VIII with five normal LS setae

9. Thoracic horn with large apical lobes in the respiratory atrium Coffmania Hazra et Chaudhuri

- Thoracic horn without apical lobes in the respiratory atrium, if present, very reduced

Conchapelopia Fittkau

10. Corona absent. Thoracic comb absent. Frontal field of thorax rugose Meropelopia Roback

- Corona present. Thoracic comb present or absent. Thorax not rugose .. 11

11. Thoracic comb present. Thoracic horn with scattered spines Telopelopia Roback

- Thoracic comb absent. Thoracic horn densely spinose ................................................................ 12

12. Horn sac well developed, completely filling respiratory atrium Metapelopia n. gen.

- Horn sac tubular and slightly sinuate, expanded distally Helopelopia Roback

Key to larvae of genera in the Thienemannimyia group

1. Middle tooth of the ligula projects distinctly beyond the otherwise straight row of teeth. Pecten hypopharyngis with about ten teeth

Xenopelopia Fittkau

- Middle tooth of the ligula smaller than lateral teeth. Pecten hypopharyngis with more than 15 teeth ....... 2

2. Maxillary palp with b-sensillum two segmented ...... 3

- Maxillary palp with b-sensillum three segmented ......

3. Pecten hypopharyngis with about 25 teeth. Middle section of pseudoradula somewhat broadened Arctopelopia Fittkau

- Pecten hypopharyngis with 15-22 teeth. Pseudoradula a uniformly broad band 4

4. Mandible with inner tooth shelf-like, distinctly projecting Telopelopia Roback

- Mandible with inner tooth barely indicated ........... 5

5. Length of antennal segment 1 divided by mandible length greater than 1.75. Distance between ventrolateral setae 2 and 3 of mandible $1 / 2$ as great as that between seta 2 and sensillum minusculum
- Length of antennal segment 1 divided by mandible length less than 1.90. Distance between ventrolateral setae 2 and 3 of mandible smaller than $1 / 2$ distance between seta 2 and sensillum minusculum ............ 8

6. Mandible broad, with straight basal tooth

Meropelopia Roback

- Mandible strongly narrowed in apical 1/2, with

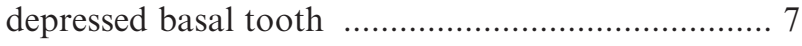

7. Ventral cephalic setae S9, S10 and SSm forming a more or less straight line diagonal to longitudinal axis of head capsule ..................Metapelopia n. gen.

- Ventral cephalic setae S9, S10 and SSm forming an $80^{\circ}-90^{\circ}$ angle ................. Amnihayesomyia Niitsuma

8. AR $>5.0$. Second antennal segment length about $40 \mu \mathrm{m}$. Sclerotized base of antennal blade about as long as wide ................... Thienemannimyia Fittkau

- AR < 5.0. Second antennal segment length about 50 $\mu \mathrm{m}$. Sclerotized base of antennal blade about twice as long as wide ............. Hayesomyia Murray et Fittkau

9. Basal tooth and accessory tooth of mandible not distinct ...................................................... 10

- Basal tooth and accessory tooth distinct ................11

10. Subbasal seta of posterior parapod unevenly bifid .... Rheopelopia Fittkau

- Subbasal seta of posterior parapod simple Coffmania Hazra et Chaudhuri

11. Basal tooth of mandible small. Pseudoradula relatively broad, granulation consisting of about eight rows. ............................... Conchapelopia Fittkau

- Basal tooth of mandible large. Pseudoradula relatively narrow, granulation consisting of about 12 rows ......

12. Ligula with median tooth slender (two times as long as wide). Middle segment of b-sensillum short (two times as long as the basal segment) ...... Lobomyia Niitsuma

- Ligula with median tooth stout (as long as wide). Middle segment of b-sensillum elongate (five times as long as wide) Helopelopia Roback

Acknowledgements. The authors are indebted to Juliano José Corbi and Cecília Santiago do Carmo Araújo for providing us with important material.

\section{References}

Epler J.H., 1988. Biosystematics of the genus Dicrotendipes Kieffer, 1913 (Diptera: Chironomidae: Chironominae) of the world. Mem. Am. Entomol. Soc., 36, 1-214.

Fittkau E.J., 1962. Die Tanypodinae (Diptera: Chironomidae). Die Tribus Anatopyniini, Macropelopiini, und Pentaneurini. Abh. Larvalsyst. Insekten., 6, 1-453.

Fittkau E.J. and Murray D.A., 1986. The pupae of Tanypodinae (Diptera: Chironomidae) of the Holarctic region - Keys and diagnoses. In: Wiederholm T. (ed.) Chironomidae of the Holarctic region - Keys and diagnoses. Part 2. Pupae. Entomol. Scand., 28, 31-113. 
Fittkau E.J. and Roback S.S., 1983. The larvae of Tanypodinae (Diptera: Chironomidae) of the Holarctic region - Keys and diagnoses. In: Wiederholm T. (ed.), Chironomidae of the Holarctic region - Keys and diagnoses. Part 1. Larvae. Entomol. Scand., 19, 33-110.

Murray D.A. and Fittkau E.J., 1989. The adult males of Tanypodinae (Diptera: Chironomidae) of the Holarctic region - Keys and diagnoses. In: Wiederholm, T. (ed.), Chironomidae of the Holarctic region - Keys and diagnoses. Part 3. Adult males. Entomol Scand., 34, 37-123.
Roback S.S., 1971. The adults of the subfamily Tanypodinae (Pelopiinae) in North America (Diptera: Chironomidae). Acad. Nat. Sci. Philadelphia, Monograph, 17, 1-410.

Sæther O.A., 1980. Glossary of chironomid morphology terminology (Diptera: Chironomidae). Entomol. Scand., 14, 1-51.

Trivinho-Strixino S., 2011. Larvas de Chironomidae (Diptera), Guia de identificação, São Carlos, 371 p.

Wiedenbrug S., 2000. Studie zur Chironomidenfauna aus Bergbächen von Rio Grande do Sul, Brazilien. Doctoral dissertation, Ludwig-Maximilians-Universität, München, 444 p. 